\title{
Condução de oficinas com grupos focais: uma pesquisa com alunos do ensino fundamental I para investigação da percepção de riscos de desastres
}

\author{
Conducting workshops with focus groups: a survey of elementary school students I to \\ investigate the perception of disaster risks
}

MENDES $^{1}$, A. F.; CARVALHO ${ }^{2}$, R. J. M.

adriciafonseca.eng@gmail.com

\begin{abstract}
Resumo
Crianças em idade escolar do ensino fundamental I passam pelo menos $20 \%$ do tempo diário e, aproximadamente, $35 \%$ do tempo que fica acordado dentro da escola. Apesar da condição de vulnerabilidade em que poderão se encontrar, as crianças não podem ser vistas como vítimas passivas frente aos desastres, porque, elas podem agir nestas situações, e também participar de todos os assuntos que afetam suas vidas. Diante disso, esta pesquisa visa conhecer qual é a percepção que os alunos do $5^{\circ}$ ano do Ensino Fundamental I de uma escola pública estadual do bairro de Mãe Luíza (Natal/RN) têm dos riscos de desastres relacionados ao bairro onde moram/estudam e suas escolas. Para tanto, foram realizadas quatro oficinas em que os alunos foram convidados a falar sobre suas percepções acerca de riscos de desastres, a partir dos seguintes temas motivadores: noções de desastres, causas dos desastres, possibilidade da ocorrência dos desastres, memórias do deslizamento de terra ocorrido em 2014 no bairro de Mãe Luíza, comunicação referente ao risco de desastres e relação entre a comunidade e as instituições envolvidas na gestão de risco de desastre. Dentre os principais resultados estão as dificuldades demonstradas pelos alunos referentes à compreensão da noção de desastres e de suas causas e a limitação do conhecimento que eles têm do órgão de Proteção e Defesa Civil municipal. Pretende-se com os resultados desta pesquisa contribuir com a formulação de políticas públicas e ações de proteção e defesa civil.
\end{abstract}

Palavras-Chave: Crianças, escola, percepção de riscos de desastres.

\begin{abstract}
Childrens in elementary school I spend at least $20 \%$ of their daily time and, nearly, 35\% of their awoken time inside the school. Despite the condition of vulnerability that they may encounter, the childrens can not be seen as passive victims in front of disasters, because, they can act in these situations, and also participate in all matters that affect their lives. On the face of this, this research aims to know what is the perception that the students from the 5th graders of the Elementary School I from a state public school of the burgh Mãe Luíza (Natal/RN) have of the risks of disasters related to the burgh where they live/study and their schools. Therefore, four workshops were held in which the students were invited to talk about their perceptions about disasters risks, from the following motivating themes: notions about disasters, causes of disasters, possibility of disasters occurrence, memories of the landslide occurred in 2014 in the Mãe Luíza neighborhood, communication on disaster risk and relation between the community and the institutions involved in disaster risk management. Among the main results are the difficulties demonstrated by the students relating to the understanding the notion of disasters and their causes and the limitation of knowledge that they have about the municipal organ Civil of Protection and Defense. It is intended with the results of this research to contribute to the formulation of public policies and actions of protection and civil defense.
\end{abstract}

Keywords: Children, school, perception of disaster risks.

\footnotetext{
${ }^{1}$ Adricia Fonseca Mendes, Programa de Pós-Graduação em Engenharia de Produção, Universidade Federal do Rio Grande do Norte, Natal-RN, Brasil.

${ }^{2}$ Ricardo José Matos de Carvalho, Programa de Pós-Graduação em Engenharia de Produção, Universidade Federal do Rio Grande do Norte, Natal-RN, Brasil.
} 


\section{INTRODUÇÃO}

As crianças, juntamente com idosos e pessoas com deficiência, são afetadas pelos desastres de forma mais agravante que outros segmentos da população. Especialmente em relação às crianças, de acordo com Seballos et al. (2011), há uma projeção de que os desastres afetem cerca de 175 milhões de crianças por ano na década compreendida entre 2011 e 2021. Entretanto, a vulnerabilidade das crianças pode ser minimizada - além das várias ações no meio em que estão inseridas - com ações que auxiliem-nas a potencializarem a percepção dos riscos em seu entorno, para que fiquem aptas a assumirem desempenhos resilientes frente aos riscos de desastres (RONAN et al., 2001).

Esta pesquisa surge numa perspectiva que protagoniza atores sociais presentes nos processos decisórios promovidos no tocante à redução de riscos de desastres. Nesta perspectiva, a literatura sociológica da construção social do risco defende que o risco não pode ser tratado a partir de uma visão técnica absoluta e objetiva, mas como objeto de construção social por grupos sociais diferenciados (VARGAS, 2009).

De acordo com Finlay e Fell (1997) apud Mendonça e Gullo (2017), se não há investigações sobre os sentimentos e juízos (percepção de riscos) dos moradores, as decisões propostas para a redução do risco serão baseadas em suposições em nome de um público que não foi consultado. Neste âmbito, a percepção de riscos consiste em um componente crucial da avaliação dos riscos realizada pela comunidade (BEMPAHA; ØYHUS, 2017).

O conhecimento da percepção de riscos de desastre das crianças é de extrema importância, para se entender sua vulnerabilidade frente aos riscos de desastres e se elaborar e implementar estratégias que ajudem a minimizar esta vulnerabilidade e, com isso, diminuir o número de vítimas, nesse segmento populacional, decorrentes de desastres.

Vários são os fatores, alguns aparentemente paradoxais, que tornam relevante o esforço de se conhecer a percepção de riscos de desastre das crianças, quais sejam: a condição de vulnerabilidade que as crianças se encontram (BRASIL, 2002; UNICEF, 2012; CHILDS, 2016), o direito em participar de todos os assuntos que afetam suas vidas (UNICEF, 1989), a desconsideração das suas opiniões nos processos públicos decisórios (UNICEF, 2009), a fragilidade dos aparelhos de proteção (VALENCIO, 2009), e a carência do tema na literatura disponível (RONAN et al., 2001; LONDE et al., 2014; JOHNSON, 2014, RONOH; GAILLARD; MARLOWE, 2015).

Neste sentido, esta pesquisa visa contribuir para a proteção das crianças frente à situação de risco de desastres, através da busca do conhecimento sobre a percepção de risco 
de desastres deste público, a qual, se compreendida poderá: orientar a formulação de políticas públicas e ações de proteção e defesa civil (como treinamento/preparação e melhorias nas instalações escolares e no bairro), fornecer base para entender e antecipar o comportamento desta população frente à tal risco, promover a elaboração de estratégias de comunicação próprias (SLOVIC, 1987; SOUZA; ZANELLA, 2009) e incentivar à gestão participativa (MENDONÇA; GULLO, 2017; SOUZA; ZANELLA, 2009) para que medidas de sobrevivência, desenvolvimento e proteção sejam adequadas e apropriadas à este público (UNICEF, 2009) de modo a reduzir efetivamente os riscos de desastres e o número de vítimas entre este público escolar.

Cabe destacar que crianças em escolas inseguras estão entre o conjunto de pessoas mais vulneráveis aos desastres (UNISDR, 2010). Escolas inseguras incluem aquelas que não possuem infra-estrutura resiliente a desastres e/ou que não abordam a gestão do risco de desastres nas atividades escolares (UNISDR, 2010). A terminologia também contempla as escolas localizadas em regiões propensas a risco de desastres (UNISDR, 2010).

Diante do exposto, o presente artigo tem como objetivo investigar a percepção de riscos de desastres de alunos do $5^{\circ}$ ano do Ensino Fundamental I de uma escola pública estadual localizada no bairro de Mãe Luíza (Natal/RN), utilizando-se, como estratégia metodológica, a realização de oficinas, a partir da formação de Grupos Focais (GF) na referida escola.

O bairro de Mãe Luíza (Natal/RN) tem sido atingido por diversos desastres ao longo dos anos, um dos quais ocorreu entre os dias 13 e 15 de junho de 2014, gerando alto impacto, com a formação de uma imensa cratera, resultante de um deslizamento de terra, em uma das suas principais ruas. A distância entre a extinta cratera e a escola onde esta pesquisa foi desenvolvida é de aproximadamente 110 metros, apenas. De acordo com a diretora e a coordenadora pedagógica da Escola de Mãe Luíza - EML (nome fictício dado à escola pesquisada, para efeito deste artigo), a instituição apresenta diversos problemas estruturais em suas instalações. Observou-se, também, que o layout da escola e as soluções arquitetônicas não são favoráveis à evacuação emergencial da comunidade escolar, caso necessário.

A estrutura do presente artigo está organizada em cinco seções. A primeira seção trata da corrente introdução, que contém, especialmente, uma breve contextualização do tema, o objetivo e a justificativa da pesquisa. Na segunda seção, é descrita a metodologia utilizada, situando uma contextualização acerca dos métodos empregados, local da pesquisa, participantes, estratégias utilizadas, tratamento e análise dos dados. Na terceira seção, são 
apresentados e discutidos os resultados. Na quarta seção, são realizadas as considerações finais resultantes desta pesquisa. Por fim, a quinta seção, trata das referências utilizadas.

\section{METODOLOGIA DA PESQUISA}

\subsection{A proposta das oficinas com Grupos Focais (GF)}

As crianças podem expressar suas opiniões livremente e participar de todos os assuntos que afetam suas vidas (UNICEF, 1989), e especificamente em relação aos desastres, lhes cabe o direito de empoderamento e participação inclusiva, acessível e não discriminatória com garantia à espaço e modos de contribuição (UNISDR, 2015).

Neste contexto, reconhecendo-se a importância de proporcionar às crianças espaços de fala, troca e ação, de modo que suas opiniões e necessidades sejam consideradas (PÉREZ; JARDIM, 2012), escolheu-se realizar oficinas, com a formação de Grupos Focais (GFs). Estas oficinas consistem em formas de trabalho que permitem levantar o saber específico das crianças (PÉREZ; JARDIM, 2012), também podem ser realizadas através de uma abordagem inclusiva, que possibilite a interação do grupo (COOPER; BABER, 2005; MORGAN et al., 2002) focal em questão.

Esta pesquisa foi desenvolvida através da realização de quatro oficinas, com o intuito de levantar as percepções de risco de desastres dos alunos do $5^{\circ}$ ano do Ensino Fundamental I de uma escola pública estadual localizada no bairro de Mãe Luíza, em Natal-RN, Brasil. Cada oficina foi composta por um GF, cada um constituído de três a oito alunos com faixa-etária compreendida entre 9-14 anos. As oficinas foram gravadas com a autorização dos pais das crianças e das próprias crianças, mediante a assinatura, respectivamente, dos Termos de Consentimento Livre e Esclarecido (TCLE) e de Assentimento Livre e Esclarecido (TALE) bem como dos Termos de Autorização para Gravação de Voz e para Uso de Imagens (Fotos e Vídeos).

Nas oficinas os alunos foram convidados a falar sobre suas percepções acerca de riscos de desastres, a partir dos seguintes temas motivadores: noções de desastres, causas dos desastres, possibilidade da ocorrência de certos eventos (considerados por eles como desastres), memórias do deslizamento de terra ocorrido em 2014 no bairro de Mãe Luíza, comunicação referente ao risco de desastres e relação entre a comunidade e as instituições envolvidas na gestão de risco de desastre. 


\subsection{Local da pesquisa}

A pesquisa ocorreu em uma escola que neste artigo é denominada Escola de Mãe Luíza (EML), visando garantir o seu anonimato. Na EML, segundo dados da coordenadora pedagógica da escola, neste ano de 2018, estudam, diariamente, de $2^{\mathrm{a}}$ a $6^{\mathrm{a}}$ feiras, 88 alunos no turno da manhã, 55 alunos no turno da tarde e 76 alunos no turno da noite, totalizando 219 alunos, afora a quantidade de professores e funcionários.

\subsection{Participantes da pesquisa}

A EML tem duas turmas do $5^{\circ}$ ano do Ensino Fundamental I, são elas: $5^{\circ}$ ano $\mathrm{A}$ (dezoito alunos matriculados) e $5^{\circ}$ ano B (dezessete alunos matriculados), ambas do turno vespertino, totalizando trinta e cinco alunos, sendo que onze destes ainda estão em processo de alfabetização e seis alunos apresentam deficiência intelectual. Em razão do elevado número de faltosos, participaram desta pesquisa doze alunos do $5^{\circ}$ ano $\mathrm{A}$ e onze alunos do $5^{\circ}$ ano $\mathrm{B}$, totalizando vinte e três alunos (sete meninos e dezesseis meninas).

A faixa-etária dos alunos, compreendida entre 9-14 anos (Médias das idades = 11,174; Desvio padrão = 1,267; Idade modal = 11 anos), foi intencional, devido ao fato de que a partir dos onze anos de idade o pensamento formal torna-se possível, isto é, as operações lógicas começam a ser transpostas do plano de manipulação concreta para o das ideias, expressas em linguagem qualquer (PIAGET, 1999).

Do total de participantes, 86,96\% $(\mathrm{n}=20)$ relatou morar em Mãe Luíza há mais de quatro anos, enquanto que $13,04 \%(n=3)$ relatou morar no referido bairro há menos de quatro anos. Vale destacar, portanto, que a grande maioria destes alunos moravam no bairro no período em que ocorreu o referido desastre, em junho de 2014. Cabe ressaltar também que, nesta pesquisa, procurou-se evitar a dependência de pais de alunos, funcionários ou professores da escola para complementar a percepção de riscos de desastres dos alunos.

\subsection{Estratégias de condução das oficinas com GFs}

As visitas oficiais à EML iniciaram em 07 de junho de 2018 logo após autorização concedida pela Secretaria Estadual da Educação e da Cultura do RN (SEEC) e pela diretora da referida escola. Nas ocasiões, entre os dias 07/06/2018 e 23/07/2018, ocorreram cinco reuniões de esclarecimentos acerca da pesquisa com professores, pais/responsáveis dos alunos e alunos do $5^{\circ}$ ano da EML. Após a coleta das assinaturas nos TCLEs e TALEs, foram realizadas quatro oficinas no período compreendido entre 25 e 26 de julho e 07 de agosto de 
2018 em uma sala de aula vazia da EML, com duração aproximada de uma hora e meia (90min) cada, sem intervalo, durante o horário escolar.

As estratégias de condução das oficinas com os quatro GFs foram baseadas em Morgan et al. (2002): cada grupo variaria em tamanho de cinco a oito alunos, com base em critérios relacionados à inibição e distração dos participantes (em razão da ausência dos alunos, na quarta oficina o GF foi composto por três alunos apenas); os assentos dos participantes e da pesquisadora foram voltados a reduzir o relacionamento hierárquico adultocriança de modo que no chão a pesquisadora esteve no mesmo nível que os participantes (Figura 1); em cada oficina foi realizado um jogo de bola em roda voltado a reforçar a participação e a coesão de cada GF e a redução de uma possível ansiedade relacionada à participação (Figura 1).

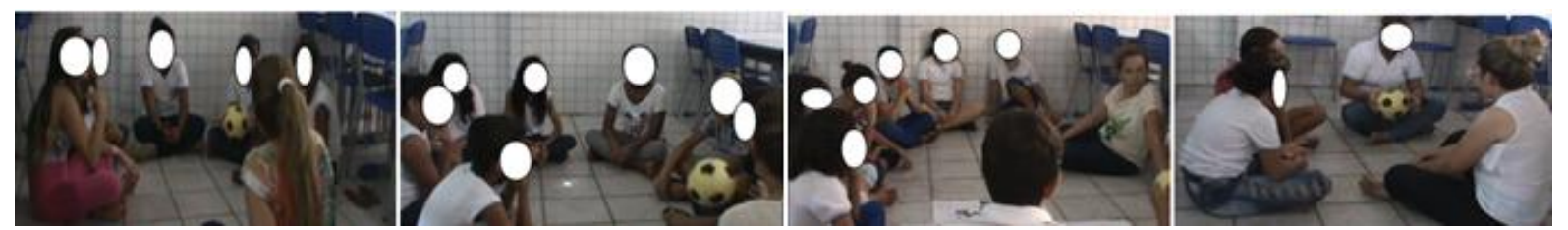

Figura 1: Jogo de bola em roda nas oficinas com GF na Escola de Mãe Luíza. Fonte: Pesquisa de campo (2018)

As oficinas foram conduzidas por uma dupla de facilitadores: um deles foi a própria pesquisadora, que ficou responsável por conduzir as discussões, e o outro ficou atento aos materiais necessários e ao registro dos encontros (fotografias e gravações de vídeos), conforme proposto por Morgan et al. (2002).

\subsection{Análise dos dados}

Os dados das oficinas, que são as falas e comportamentos registrados a partir da filmagem, foram transcritos e descritos, respectivamente, pela pesquisadora e, em seguida, foram tratados e analisados os conteúdos das falas para o estabelecimento de categorias relacionadas ao tema "percepção de riscos de desastres".

\section{RESULTADOS E DISCUSSÕES}

Como mencionado no tem 2.5, foram estabelecidas categorias de análise dos dados, que relacionam as falas dos participantes, tendo sido escolhidas aquelas que exemplificam a categoria com a percepção de risco de desastres dos alunos. 


\subsection{Desastres: O que são?}

Quando os alunos discutiram o que para eles são desastres, os relatos demonstram que o entendimento que eles têm à respeito, está relacionado ao deslizamento de terra que ocorreu em 2014 no bairro de Mãe Luíza e às diversas situações percebidas como desastres.

\footnotetext{
Aquilo que aconteceu em Mãe Luíza (Aluna S, 13 anos).

Eu vi um vídeo de um desastre, a mulher tava gravando um vídeo de uma corrida, os carros vinham muito rápido, aí de repente um carro bateu no outro, aí estragou o vídeo e o homem ficou muito ferido (Aluna D, 9 anos).

[No desastre] tem muita brincadeira que nós não gosta. Chamar nós de algum palavrão (Aluna U, 11 anos).

Gente jogando lixo no meio da rua, matando pai matando filho [...] (Aluno F, 10 anos).
}

É possível verificar pelas falas que a noção do termo desastre é ampla e ainda não está bem compreendida pelas crianças. Isso pode estar relacionado a alguns fatores, como o fato dos alunos não receberem educação sobre risco de desastres na escola e tratarem muito pouco sobre este assunto com a família e na comunidade onde vivem.

\subsection{Causas dos desastres}

Nos relatos seguintes os alunos atribuem as causas das ocorrências dos eventos (que eles consideram como desastres) às ações humanas.

\footnotetext{
Quando alguém bebe que fica no celular e fica dirigindo (Aluna D, 09 anos).

Quem faz o desastre faz isso porque quer (Aluno K, 11 anos).
}

No tocante ao deslizamento de terra ocorrido em Mãe Luíza, todos os alunos atribuíram a causa do evento à chuva e não às ações humanas, denotando naturalização de sua causa. O relato seguinte demonstra que a percepção das causas do evento mencionado podem estar relacionadas às informações transmitidas por membro da comunidade.

\footnotetext{
Eu já conversei sobre desastre com a minha tia, eu perguntei a ela como foi esse desastre [deslizamento de terra ocorrido em Mãe Luíza], ela explicou que ele ocorreu por causa da chuva (Aluna C, 11 anos).
}

Embora os alunos tenham atribuído à causa do deslizamento de terra às chuvas, o fato é que as causas da condição do risco de deslizamento que caracteriza a área de Mãe Luíza onde ocorreu o desastre são (MPRN, 2016): ausência de controle sobre a ocupação do solo, instabilidade do solo e precariedade do funcionamento do sistema de saneamento, bem como ausência de ações sistematizadas dirigidas à prevenção ou ao controle do risco que caracteriza a área afetada, seja do órgão público municipal responsável pela gestão da ocupação do solo, 
seja de outros órgãos públicos ou agências concessionárias dos serviços públicos municipais e estaduais.

É notável que a percepção das causas do deslizamento de terra foi tida como "externa", já que qualquer solução sugerida não os inclui (alunos), e isso poderá levá-los a uma postura conformista ao considerarem que os desastres são inevitáveis. Diante do exposto, fica claro que há eventos que os alunos conseguem facilmente atribuir a sua ocorrência às ações humanas, enquanto que em outros, isso não ocorre.

\subsection{Desastres: eventos inevitáveis e irreversíveis?}

Os alunos muito divergiram no que se refere a se os desastres podem ou não ser evitados ou reversíveis. No relato, a seguir, é possível verificar o motivo apresentado por um aluno que acredita que os desastres são irreversíveis.

\footnotetext{
Porque se faz uma coisa, tipo, não pode voltar no tempo, vai ter que ficar pro resto da vida [...] Tipo eu derrubei alguma coisa da senhora [pesquisadora], celular da senhora, não posso voltar no tempo (Aluno F, 10 anos).
}

Dentre alguns alunos que reconheceram que o deslizamento de terra ocorrido em Mãe Luíza poderia ter sido evitado, apenas um deles mencionou como isso seria possível, indicando ações de prevenção dos riscos.

Eu vou dizer porque que podia ser evitado [o deslizamento de terra em Mãe Luíza], podia ter colocado coluna nos muros, fazer com mais cimento pra segurar mais firme (Aluno T, 11 anos).

De fato, controles efetivos que incluem edificações construídas sobre muros de arrimo e graus de impermeabilização dos solos dos espaços públicos foram algumas das medidas recomendas para que novos deslizamentos fossem evitados ou controlados (MPRN, 2016).

\subsection{Desastre(s) mais provável(is) de acontecer}

Os alunos falaram sobre os desastres que eles acreditavam ser os mais prováveis de acontecer na escola, no bairro onde moram e na cidade de Natal. Cabe destacar que todos os alunos que participaram da presente pesquisa moram no bairro de Mãe Luíza.

\subsubsection{Na escola:}

Alguns relatos apontam riscos de desabamentos, acidentes e deslizamentos.

As paredes podem cair [...] Se der muita chuva vai cair aquele morro [a aluna apontou para o morro] [..] mas se Deus quiser, Deus vai botar uma pessoa pra ajeitar. Se cair aqui na escola, Deus me livre, a gente vai ficar sem estudar né? (Aluna A, 10 anos). 
O ventilador pode até cair na cabeça de algum aluno (Aluna C, 11 anos). $\mathrm{O}$ parque pode cair, uma vez os gêmios tavam brincando, vi que ficou virando assim o balanço, ia virando os paus (Aluna D, 09 anos).

Em relação ao risco de desabamento, de acordo com a coordenadora pedagógica da EML, a escola apresenta diversos problemas estruturais nas suas instalações. A diretora da EML afirma que foram realizadas várias solicitações de reforma à Secretaria Estadual de Educação e Cultura do RN, mas não se obteve êxito.

\subsubsection{No bairro onde moram (Mãe Luíza) e na cidade de Natal:}

Foram frequentes os relatos dos alunos acerca dos riscos de desabamento dos prédios localizados no bairro de Mãe Luíza. A frequência dos relatos sugere que os alunos reconhecem os riscos de desabamento dos edifícios verticalizados. Esta percepção pode estar relacionada à vivência do deslizamento (vinte e seis famílias perderam suas casas) e às notícias transmitidas pela mídia e comunidade acerca de possíveis danos às estruturas dos prédios em decorrência do deslizamento de terra ocorrido (MPRN, 2016).

O relato seguinte demonstra a relação entre percepção de risco e educação sobre risco de desastres. A aluna reconheceu os riscos de alagamento e deslizamento no bairro de Mãe Luíza, devido o professor já ter abordado este assunto em sala de aula. Cabe destacar que esta abordagem ocorreu casualmente.

\section{O professor disse que as casas foram feitas no morro e se alagar elas podem vir descendo, então pode alagar as casas, porque aqui chove muito (Aluna $\mathrm{P}, 10$ anos).}

Também é possível verificar na fala de um aluno a relação entre a percepção de risco e a vivência do deslizamento de terra ocorrido. Segundo o aluno, o desastre mais provável de ocorrer em Mãe Luíza é:

Um buraco (Aluno R, 11 anos).

É provável que os alunos estejam avaliando o risco de deslizamento como alto em função do efeito da vivência do evento. Dados do Plano Municipal de Redução de Riscos do Município de Natal (PMRR, 2008) revelam que os riscos de deslizamentos e alagamentos relatados pelas crianças não são superestimados. O bairro de Mãe Luíza está localizado em uma área de risco alto e muito alto de desastre (NATAL, 2008) e especialmente para a área afetada pelo deslizamento é possível identificar o "grau 4", índice relativamente alto, para a condição de risco de deslizamento de solo (NATAL, 2008; MPRN, 2016). 
3.5 Vivência do deslizamento de terra ocorrido em 2014 no bairro de Mãe Luíza (Natal/RN)

Várias crianças relataram terem vivenciado o deslizamento de terra que ocorreu em 2014 no bairro de Mãe Luíza. Isso deve-se ao fato de que 86,96\% ( $\mathrm{n}=20$ ) dos alunos informaram morar em Mãe Luíza há mais de quatro anos. É possível evidenciar, consideravelmente, no relato seguinte, as memórias das perdas humanas, perdas materiais e danos sociais e psicológicos sofridos em decorrência do evento.

\footnotetext{
Casa indo simbora, tem gente que morreu, que assim um pessoa morreu né? Foi carro simbora. O desastre foi de noite eu me lembro que eu tinha 6 anos e a gente tudo dentro de casa minha família todinha na minha casa e todo mundo ficou perturbado. Minha mãe passou mal [...] no outro dia minha mãe ainda estava no hospital e minha avó também estava muito doente e ela já é uma senhora de idade. Minha avó quem cuidou da minha mãe e quando foi no outro dia choveu, caiu um carro também, aí foi muito fio (Aluna A, 10 anos).

A minha prima disse que ela perdeu os cachorros dela no desastre e a casa dela desabou no desastre (Aluna G, 10 anos).
}

A consciência das perdas e danos pode ser devido ao tipo de informações transmitidas para as crianças através da comunidade, família ou escola e as lembranças do evento ocorrido.

Ainda no tocante à vivência do deslizamento de terra ocorrido, foram frequentes os relatos dos alunos acerca das marcações em " $x$ " em cores amarelo e vermelho realizadas em suas casas pelo Órgão de Proteção e Defesa Civil (OPDC) do município de Natal. As referidas marcações serviram de alerta para os moradores acerca da vulnerabilidade das suas edificações, de modo que as marcações em vermelho indicavam risco iminente de desabamento sendo necessária a evacuação imediata, enquanto que as marcações em amarelo indicavam que os moradores deveriam ficar em estado de alerta em relação ao agravamento da situação das suas casas.

As frequências dos relatos dos alunos demonstram a importância que o ambiente residencial tem para eles. A partir dos relatos também foi possível verificar o conhecimento que eles demonstraram ter do OPDC. Tal conhecimento está muito limitado à percepção das ações que o referido órgão desempenhou durante o deslizamento ocorrido em Mãe Luíza e, em decorrência disso, todos os alunos afirmaram que não gostariam de receber os agentes do OPDC nas casas onde moram ou na escola em que estudam.

[Agentes do OPDC] Eles podem dizer que é para sair da casa, fazer um $x$ na casa (Aluna $\mathrm{O}, 11$ anos)

[Agentes do OPDC] Eles podem dizer que a minha casa pode cair, aí eu ia ficar muito triste e ia chorar (Aluna A, 10 anos).

O relato de um aluno aponta para o medo de receber os agentes do OPDC em casa ou na escola por achar que eles andam munidos de arma: 
Sabe o que eu tenho medo? Minha mãe já disse que o policial estava com uma arma e disparou sozinha [Aluno R, 11 anos].

Fica claro que os papéis desempenhados pelo OPDC na sociedade ainda são poucos esclarecidos para as crianças. Isso demonstra que há um certo distanciamento entre o órgão e a comunidade, o que dificulta a comunicação e colaboração entre ambos, a efetividade de políticas públicas voltadas à redução do risco e a participação popular. Contudo, tal distanciamento poderá ser reduzido em virtude do interesse pela preparação/treinamento para o enfrentamento de risco de desastres demonstrado por todos os alunos.

\section{CONCLUSÕES}

As oficinas com Grupos Focais revelaram-se como importantes metodologias que permitiram a participação efetiva dos alunos, de forma que eles puderam expressar livremente o que eles sabem sobre os desastres, em um ambiente que permitiu a ocorrência de discussões interativas e o levantamento de informações valiosas referentes à percepção de risco de desastres. Nas oficinas, os alunos mantiveram-se atentos e não houve desistências.

Os resultados revelam que os alunos demonstram dificuldades referentes à compreensão da noção de desastres e de suas causas.

Os eventos (considerados pelos alunos como desastres) mais prováveis de ocorrer na escola foram desabamentos, acidentes e deslizamentos (é possível que tal reconhecimento seja em função dos sinais que indicam problemas estruturais na EML, bem como da vivência e relativa recência do deslizamento de terra ocorrido no bairro de Mãe Luíza).

Em relação ao bairro de Mãe Luíza, houve um relato de que os desastres mais prováveis de ocorrer são deslizamentos e alagamentos. Tal afirmativa deveu-se a uma informação fornecida casualmente pelo professor em sala de aula. Também foi possível identificar fortes memórias das perdas humanas, perdas materiais e danos sociais e psicológicos sofridos em decorrência do deslizamento de terra ocorrido. Além disso, ficou claro que o conhecimento que os alunos têm do órgão de Proteção e Defesa Civil municipal está limitado a algumas ações desenvolvidas pelo mesmo durante o deslizamento de terra ocorrido em Mãe Luíza, de modo que os alunos não têm conhecimento do trabalho voltado à prevenção desenvolvido pelo referido órgão.

Os alunos da EML não recebem educação sobre risco de desastres, embora tenham apresentado algum conhecimento empírico sobre o assunto. Contudo, demonstraram ter interesse em aprender sobre riscos e desastres e isso pode ser usado para incentivar, por 
exemplo, a preparação para o enfrentamento de risco de desastres, visando o desenvolvimento de atitudes e habilidades seguras e resilientes, a exemplo de exercícios simulados, de estímulos à formação de agentes mirins de proteção e defesa civil e de criação do Núcleo Comunitário Mirim de Proteção e Defesa Civil no bairro.

Considerando-se as diversas condições de vulnerabilidade, o histórico de ocorrência de eventos extremos do bairro de Mãe Luíza e a considerável vulnerabilidade de crianças menores de quinze anos (BRASIL, 2002), recomenda-se, nesta pesquisa, o desenvolvimento de ações educativas e informativas sistemáticas nas escolas, referentes à preparação, prevenção e mitigação de desastres como forma de aguçar a percepção de riscos de desastres, visando o desenvolvimento de atitudes e habilidades seguras e resilientes das crianças.

\section{REFERÊNCIAS}

BEMPAHA, Sherry Adomah; ØYHUS, Arne Olav. The role of social perception in disaster risk reduction: Beliefs, perception, and attitudes regarding flood disasters in communities along the Volta River, Ghana. International Journal Of Disaster Risk Reduction, [s.1.], v. 23, p.104-108, ago. 2017. Elsevier BV. http://dx.doi.org/10.1016/j.ijdrr.2017.04.009.

BRASIL. Redução das vulnerabilidades aos desastres e acidentes na infância. Ministério da Integração Nacional. Secretaria Nacional de Defesa Civil. 2. ed. Brasília: MI, 2002. 72 p. Disponível

em: $<$ http://bvsms.saude.gov.br/bvs/publicacoes/reducao_vunerabilidades_desastres_infancia. pdf>. Acesso em: 09 dez. 2017.

CHILDS, Anna. Why child trafficking spikes after natural disasters - and what we can do about it. The Conversation. 2016. Disponível em: <https://theconversation.com/why-childtrafficking-spikes-after-natural-disasters-and-what-we-can-do-about-it-53464> Acesso em: 12 de mai. de 2018.

COOPER, Lee; BABER, Christopher. Focus Groups. In: STANTON, Neville et al. Handbook of Human Factors and Ergonomics Methods. CRC Press LLC, 2005. p. 1-7.

MENDONÇA, Marcos Barreto de; GULLO, Fernanda Teles. Percepções de risco associado a deslizamentos em Angra dos Reis, Rio de Janeiro. In: MARCHEZINI, Victor et al (Org.). Redução de vulnerabilidade a desastres: Do conhecimento à ação. São Carlos: Rima Editora, 2017. Cap. 21. p. 477-497.

MPRN, Ministério Público do Rio Grande do Norte. Petição Inicial. 2016. Disponível em: <http://www.mprn.mp.br/portal/files/ACP-Peticao_Inicial_-_P2.pdf.> Acesso em 20 de jan. de 2018.

MORGAN, Myfanwy et al. Hearing children's voices: methodological issues in conducting focus groups with children aged 7-11 years. Qualitative Research, [s.1.], v. 2, n. 1, p.5-20, abr. 2002. SAGE Publications. http://dx.doi.org/10.1177/1468794102002001636 
PÉREZ, Beatriz Corsino; JARDIM, Marina Dantas. Vamos ouvir as crianças?: caderno de metodologias participativas Projeto Criança Pequena em Foco. Rio de Janeiro: CECIP, 2013. $48 \mathrm{p}$.

PIAGET, Jean. Seis Estudos de Psicologia. 24. ed. Rio de Janeiro: Forense Universitária, 1999.

RONAN, Kevin R. et al. School Children's Risk Perceptions and Preparedness: A Hazards Education Survey. The Australasian Journal Of Disaster And Trauma Studies, v. 2001-1, p.1-29, 2001.

RONOH, S; GAILLARD, Jc; MARLOWE, J. Children with disabilities and disaster preparedness: a case study of Christchurch. Kōtuitui: New Zealand Journal of Social Sciences Online, [s.1.], v. 10, n. 2, p.91-102, 3 jul. 2015. Informa UK Limited. http://dx.doi.org/10.1080/1177083x.2015.1068185.

SEBALlOS, Fran et al. Children and Disasters: Understanding Impact and Enabling Agency. Brighton: Children In a Changing Climate, Institute Of Development Studies, 2011. SLOVIC, Paul. Perception of Risk. Science, v. 236, p., 280-285, 1997.

SOUZA, Lucas Barbosa; ZANELLA, Maria Elisa. Percepção de Riscos Ambientais: Teoria e Aplicações. Fortaleza: Edições Ufc, p.240, 2009.

VARGAS, Dora. "Eu fui embora de lá, mas não fui": A construção social da moradia de risco. In: VALÊNCIO, Norma et al (Org.). Sociologia dos desastres: Construção, interfaces e perspectivas no Brasil. São Carlos: Rima Editora, 2009. 280 p. Cap. 7. p. 80-95.

VALENCIO, Norma. Da morte da Quimera à procura de Pégaso: A importância da interpretação sociológica na análise do fenômeno denominado desastre. In: VALÊNCIO, Norma et al (Org.). Sociologia dos desastres: Construção, interfaces e perspectivas no Brasil. São Carlos: Rima Editora, 2009. 280 p. Cap. 2. p. 3-18.

UNICEF. A Convenção sobre os Direitos da Criança. 1989. Disponível em: $\langle$ https://www.unicef.pt/docs/pdf_publicacoes/convencao_direitos_crianca2004.pdf $>$.

Acesso em: 9 set. 2017.

Situação mundial da infância. Celebrando 20 Anos da Convenção sobre os Direitos da Criança. $2009 . \quad$ Disponível em:< https://www.unicef.org/brazil/pt/sowc_20anosCDC.pdf>. Acesso em 27 ago. 2018.

.UNICEF and Disaster Risk Reduction. 2012. Disponível em: <http://www.unicef.org/files/DDR_final.pdf>. Acesso em: 9 set. 2017.

UNISDR. Advocacy Guide. One Million Safe Schools and Hospitals Campaign. 2010.Disponívelem:<http://www.unisdr.org/files/15656_1msshadvguideprefinal0318101.pdf $>$ Acesso em: 7 ago. 2018. 
Sendai Framework for Disaster Risk Reduction 2015-2030. 2015. Disponívelem:<https://www.preventionweb.net/files/43291_sendaiframeworkfordrren.pdf> Acesso em: 15 out. 2017.

Recebido em: 13/04/2019

Aceito para publicação em: 25/05/2019 